COVER ESSAY

\title{
GASP: picking off the pack of lies
}

\section{Farren}

Tobacco Control 2004;13:100-101. doi: 10.1136/tc.2004.008383

GASP is celebrating 25 years tackling Big Tobacco's packs of lies!

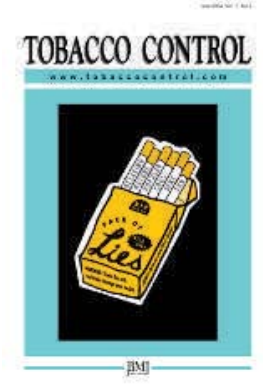

Correspondence to: Ms Cecilia Ann Farren, GASP Smoke Free Solutions, 93 Cromwell Road, Bristol BS6 5EX, UK; Cecilia@gasp.org.uk
GASP selected priority smoke-filled targets. We then went forth to survey diners, lobby managers, write letters to the press and collate the first GASP guide to smoke-free places. When we found that the renowned Harvey's restaurant (in the old wine cellars of Harvey's Bristol Cream) gave out free cigars to diners, we presented them with the "GASPing Gourmet Gas Mask Award" in recognition of the "fine wines, fresh food and foul air". When we needed a fact sheet about the health risks of tobacco smoke pollution, we wrote our first leaflet"Passive smoking: the facts" in 1981, illustrated with cartoons drawn by a GASP member. The seeds of GASP's publishing future were planted.

Buoyed by success, some GASP members turned their attention to the "lies" of tobacco's advertising and sponsorship of sport and arts. We greeted prestigious tobacco sponsored events with wild and witty demonstrations. At a series of tobacco sponsored concerts, broadcast live on BBC Radio 3, dressed in white coats with stethoscopes, we "weeded out" smokers with coughs from the audience. The John Slayer Players, in wheelchairs, with tracheal tubes or oxygen cylinders gave an alternative performance to the queuing audience. We signed up for Marlboro Adventure Holidays at Thomas Cook Travel dressed as Victorian Funeral Directors

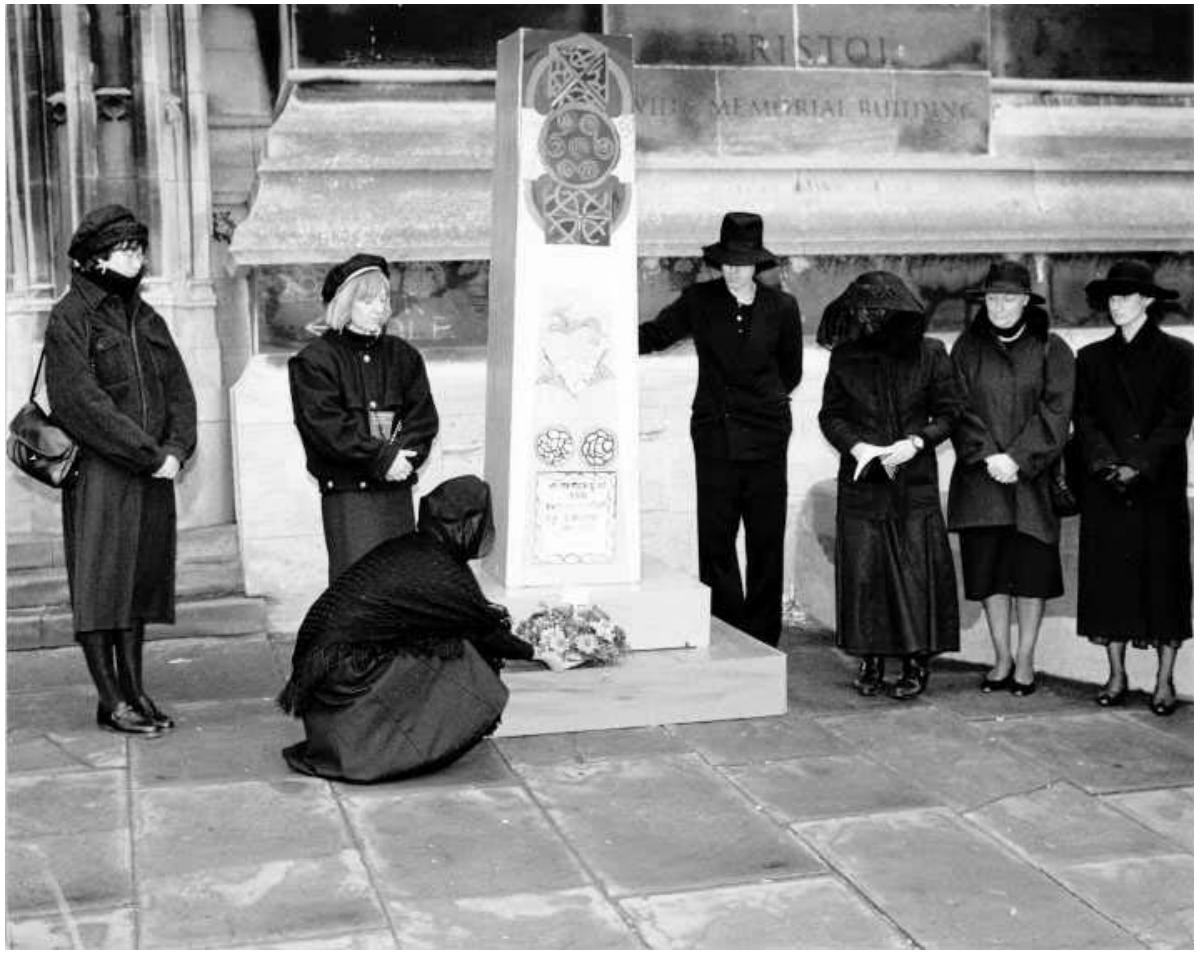

Figure 1 GASP members laying wreaths to Bristol's dead smokers outside the Wills factory and the University Wills Memorial Building. 


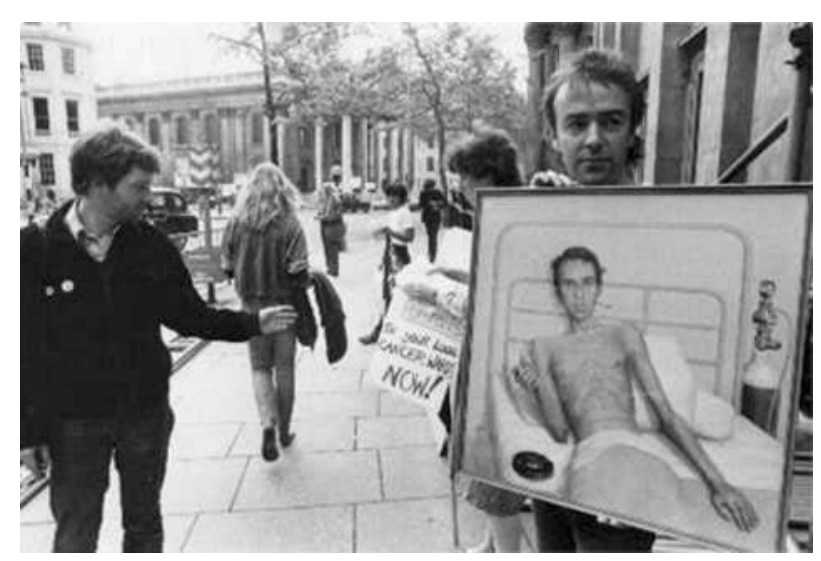

Figure 2 GASP members outside the National Portrait Gallery in London with their entry to the John Player Portrait Award-a painting of a 34 year old father of five dying from lung cancer.

accompanied by the Grim Reaper. We laid wreaths to Bristol's dead smokers outside the Wills factory and the University Wills Memorial Building paid for with tobacco money (fig 1). We staged a lung cancer operation outside a performance of Wagner's opera Gotterdammerung that we re-named "GottadamagedLung". We entered a painting of a 34 year old father of five dying from lung cancer for the John Player Portrait Award and we protested outside the high profile event at the National Portrait Gallery (fig 2). One Christmas, a giant, neon, cigar-smoking Santa Claus carrying a sack of cigars appeared over the Imperial Tobacco Cigar Factory. We protested with the "real" Santa Claus demanding that this smoky impostor be switched off. Whenever Imperial Tobacco pulls out its pack of lies with "smoking doesn't kill", "children shouldn't smoke", or "it's not addictive" then GASP responds with demonstrations led by appropriately dressed characters such as blood sucking Count Tobacula (fig 3), Pigs that Fly, Captain Hooked, or Superman with his $x$ ray vision to help others see through the "lies".

Over time GASP has tackled the pack of lies with a stack of facts. The original passive smoking leaflet has been revamped and has been joined by over 400 informative, innovative and creative resources on every aspect of tobacco control. GASP now has a glossy catalogue and website offering books, leaflets, posters, models, displays, CDs, videos and testing equipment (www.gasp.org.uk). We publish and sell materials for students, smokers, professionals, and the media. For

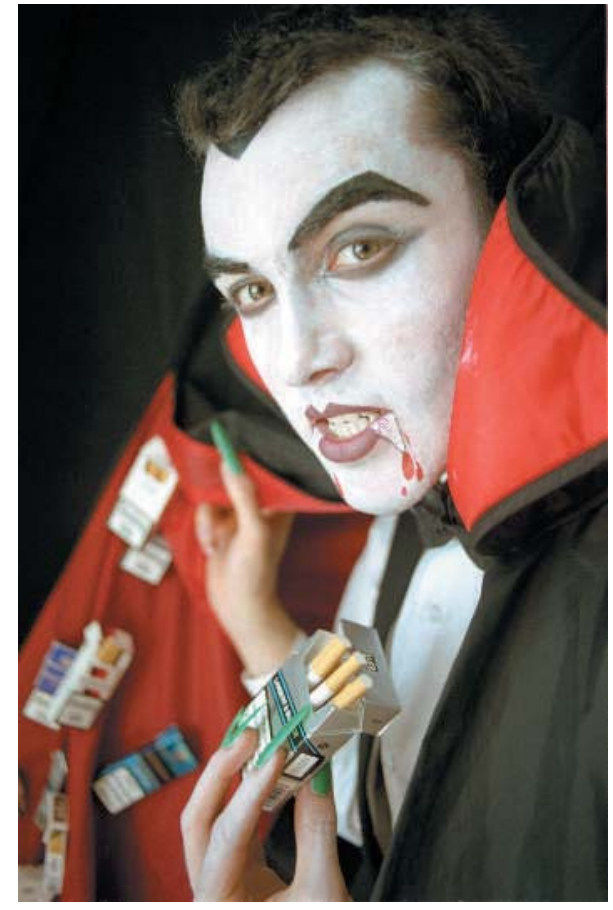

Figure 3 Count Tobacula.

different target groups we offer quit guides for women, pregnant women, parents, young people, older adults, pre-op smokers, asthmatics, blokes, impotent blokes, soldiers, South Asians, and prisoners. To test smokers we have a One-cig-ometer kit, Smokerlyzers for carbon monoxide tests, and cotinine testing kits. And for young people we have the gruesome, the witty, and the weird such as videos showing an autopsy and amputations, or a "Smokers' hairy tongue" poster voted by teens as the most off-putting side effect of smoking, or stickers that point the way to the "Secret smoking den". Best sellers for photo opportunities and media events are the Big Cig costume, Smoker's Tar in a Jar, inflatable cigarettes, a 3D display of chemicals in tobacco smoke, and a book showing how to create GASP characters such as Count Tobacula, Captain Hooked, and Death. GASP is always looking for new resources to help others to pack a punch to those lies. Let GASP know if you have produced or can recommend anything (www.gasp.org.uk). 